\title{
Triggering of erythropoietin production by hypoxia is inhibited by respiratory and metabolic acidosis
}

\author{
KAI-UWE ECKARDT, ARMIN KURTZ, AND CHRISTIAN BAUER \\ Department of Physiology, University of Zurich, CH-8057 Zurich, Switzerland
}

Eckardt, KaI-Uwe, ARMin Kurtz, AND Christian BAUER. Triggering of erythropoietin production by hypoxia is inhibited by respiratory and metabolic acidosis. Am. J. Physiol. 258 (Regulatory Integrative Comp. Physiol. 27): R678-R683, 1990.-Erythropoietin (EPO) production in response to hypoxic hypoxia is known to be attenuated by simultaneous hypercapnia. This study aimed to investigate whether this inhibitory effect of hypercapnia is 1) a direct effect of carbon dioxide or mediated by changes in $\mathrm{pH}$ or bicarbonate, 2) affects also carbon monoxide hypoxia, and 3) influences either the synthesis and release of EPO or the mechanisms by which hypoxia triggers an increase in EPO production rate. We found that EPO formation in mice exposed to normobaric hypoxia $\left(8 \% \mathrm{O}_{2}\right)$ or to carbon monoxide $(0.1 \%)$ was reduced by 30 and $42 \%$ when animals were simultaneously exposed to hypercapnia $\left(7 \% \mathrm{CO}_{2}\right)$, by 35 and $38 \%$ when subjected to metabolic acidosis $\left(\mathrm{NH}_{4} \mathrm{Cl}\right)$, and unchanged when subjected to metabolic alkalosis $\left(\mathrm{NaH}\left(\mathrm{O}_{3}\right)\right.$. In animals exposed to brief hypoxia $(15 \mathrm{~min})$ and subsequent normoxia $(2 \mathrm{~h})$, metabolic acidosis did not affect EPO levels when initiated after the hypoxic period. The results indicate that acidosis inhibits hypoxia-induced triggering of EPO formation independently of $\mathrm{PCO}_{2}$ and $\mathrm{HCO}_{3}$ levels. Because this inhibitory effect is also present during carbon monoxide hypoxia, it appears not solely due to potentiated hyperpnea. Alternatively, it may result from a facilitated intrarenal oxygen release or a direct effect at the EPO production sites.

kidney; normobaric hypoxia; functional anemia; hypercapnia; metabolic alkalosis

ERYTHROPOIETIN (EPO) is produced by renal peritubular cells in an inverse correlation with the oxygen content of arterial blood. This adaptation of EPO formation to oxygen availability appears to occur in the kidney itself and involves alterations in EPO gene transcription (21). However, the mechanisms by which changes in renal oxygen supply affect the production rate of EPO are largely unknown.

Interestingly, the increase in serum EPO levels in response to diminished inspiratory oxygen tension is attenuated when inspiratory carbon dioxide tensions are simultaneously increased $(1,3,8,14,20,25,26)$. This inhibitory effect of hypercapnia has not been fully clarified, and a number of possibilities have to be considered. The primary alteration in acid-base balance comprises an increase in $\mathrm{PCO}_{2}$ and bicarbonate levels and a decrease in $\mathrm{pH}$, and each of these changes might affect the amount of circulating EPO. The increase in $\mathrm{PCO}_{2}$ and decrease in $\mathrm{pH}$ diminish the oxygen affinity of hemoglobin, and it has been suggested that this results in increased peR678

0363-6119/90 \$1.50 Copyright (C) 1990 the American Physiological Socie $\overrightarrow{\mathrm{B}}$ ripheral oxygenation, thereby reducing the signal for EPO formation $(14,16,20,25)$. In addition, hypercarbia improves oxygen availability by increasing the ventilatory response to hypoxia, which in turn enhances arterial $\mathrm{PO}_{2}$ and oxygen saturation $(3,14,23,25)$.

Furthermore, in a variety of models, including the isolated perfused kidney (22), renal cortical slices (18), and isolated tubule preparations $(2,24)$, a protective effect of acidosis against hypoxic injury has been demonstrated. Although the subcellular mechanisms of this effect remain elusive, it is conceivable that acidosis may render the cells that govern EPO production less susceptible toward hypoxia. Alternatively, not only the signals inducing EPO formation but also the synthesis of the hormone itself or EPO clearance may be sensitive to acid-base changes, thereby affecting serum levels.

In the present study, we investigated the effect of acidbase changes on EPO production in mice to confine these possible mechanisms. First, the effects of respiratory and metabolic acidosis were compared to evaluate whether EPO responds directly to changes in systemic $\mathrm{pH}$ or is related to specific effects of changes in $\mathrm{PCO}_{2}$. Miller and co-workers (16) and Schooley and Mahlmann (20) previously reported an inhibition of EPO formation after treatment with acetazolamide, which is associated with metabolic acidosis. However, we have recently demonstrated that acetazolamide can inhibit EPO formation independent of changes in systemic acid-base status, presumably by inhibition of proximal tubular sodium reabsorption (6). Therefore, the effect of a systemic metabolic acidosis on EPO production had to be reassessed. Second, to evaluate the role of an acidosis-induced increase in ventilation for the suppression of EPO levels, we examined the effect of acid-base changes on hypoxia induced by carbon monoxide inhalation. Under this condition of diminished oxygen transport capacity, an increased ventilation cannot significantly enhance peripheral oxygenation. However, previous reports on the effect of hypercapnia on increases in EPO levels after reductions in oxygen-carrying capacity are conflicting; whereas Faura and co-workers were unable to demonstrate a suppression of EPO levels in anemia (8), Miller and Howard found a significant reduction (14). Third, we used a combination of short-term hypoxia and subsequent normoxia to separate an initial phase of signal transduction from subsequent hormone synthesis, to evaluate the effect of acid-base alteration on each phase.

Our results indicate that hypoxia-induced EPO formation is inhibited by a decrease in systemic $\mathrm{pH}$, irre- 
spective of the way by which it is brought about, and that this inhibition affects the mechanisms triggering an increase in EPO formation but not hormone synthesis itself.

\section{MATERIALS AND METHODS}

Institute of Cancer Research (ICR) strain male mice (body wt 27-34 g) were used in this study. Animals had free access to standard laboratory chow and tap water before and during the experiments.

Hypoxic stimulation of EPO formation. Normobaric arterial hypoxia or functional anemia caused by carbon monoxide inhalation were used to stimulate EPO formation, as described (6). In brief, animals were exposed for $3 \mathrm{~h}$ to atmospheres low in oxygen $\left(8 \% \mathrm{O}_{2}\right.$ and balance $\mathrm{N}_{2}$ ) or normal air with added carbon monoxide $(0.1 \%)$. Within 15 min after termination of hypoxia, animals were bled from the retroorbital sinus for determination of serum EPO levels.

In a separate set of experiments, designed to distinguish the induction of EPO formation from a subsequent phase of hormone synthesis, animals were exposed to $8 \%$ $\mathrm{O}_{2}$ for 5-40 min and thereafter exposed to normoxia for an additional $1-2.5 \mathrm{~h}$ before blood sampling.

Induction of alterations in acid-base status. To study the effect of respiratory acidosis on hypoxia-induced EPO levels, animals were exposed to atmospheres of 1) $8 \% \mathrm{O}_{2}$ together with 5,7 , or $10 \% \mathrm{CO}_{2}$ and balance $\mathrm{N}_{2}$ or 2) $0.1 \% \mathrm{CO}, 20 \% \mathrm{O}_{2}$, and $7 \% \mathrm{CO}_{2}$. Previous studies employing hypoxia of comparable duration and severity in rats or rabbits $\left(7.5-8.8 \% \mathrm{O}_{2}\right)$ have shown that the addition of $5-5.6 \% \mathrm{CO}_{2}$ or $10 \% \mathrm{CO}_{2}$ increases arterial $\mathrm{PCO}_{2}$ from $15.9-27.9$ to $41.4-48.1$ and $70.8 \mathrm{mmHg}$ and reduces blood $\mathrm{pH}$ from $7.43-7.51$ to $7.30-7.37$ and 7.28, respectively $(3,14,25)$.

Metabolic acid-base disturbances were induced by application of ammonium chloride (metabolic acidosis) or sodium bicarbonate (metabolic alkalosis). One-molar solutions of ammonium chloride and sodium bicarbonate were injected $50 \%$ intraperitoneally and $50 \%$ subcutaneously at a dose of 10 and $20 \mathrm{mmol} / \mathrm{kg}$ body wt, respectively, immediatly before the onset of hypoxia. In those experiments, comprising a first interval of hypoxia and a second interval of normoxia, ammonium chloride was injected immediately before or after termination of hypoxia. Control animals were treated with identical volumes of equimolar sodium chloride and simultaneously exposed to the respective hypoxic stimuli.

Determination of EPO. EPO was measured in serum by radioimmunoassay as described (7), using a rabbit antiserum raised against recombinant human EPO and iodinated recombinant EPO (Amersham International, Amersham, UK) as tracer. A mouse serum pool enriched in EPO, prepared and calibrated by in vivo bioassay as described (6), was used as a standard.

Determination of acid-base parameters. To assess the effect of ammonium chloride and sodium bicarbonate treatment on acid-base status, $\mathrm{pH}$ and standard bicarbonate concentrations in peripheral venous blood were determined. Animals were anesthetized with $400 \mathrm{mg} / \mathrm{kg}$ body wt 5-ethyl-(1'-methylpropyl)-2-thiobarbituric acid
(Inactin, Byk-Gulden, Constance, FRG) injected intraperitoneally in a concentration of $100 \mathrm{mg} / \mathrm{ml}$. Immediately after onset of anesthesia they were bled from the retroorbital sinus into heparinized glass capillary tubes that were then instantly transferred to a computerized blood gas analyzer (IL 1304, Instrumentation Laboratory, Lexington, $\mathrm{MA}$ ) for determination of $\mathrm{pH}, \mathrm{Po}_{2}$, and $\mathrm{PCO}_{2}$ with the appropriate electrodes. Oxygen saturation was estimated from $\mathrm{PO}_{2}$ using an oxygen dissociation curve that was previously determined by tonometry of pooled mouse blood. Standard bicarbonate concentrations were calculated employing the values for $\mathrm{pH}, \mathrm{PCO}_{2}$, and oxygen saturation in standard formulas.

Statistics. Statistical analysis was performed by use of Student's $t$ test with Bonferroni's reduction for multiple comparisons. $P<0.05$ was considered significant.

\section{RESULTS}

Effect of acid-base alterations on EPO production under hypoxic hypoxia. The effect of increasing concentrations of carbon dioxide in the inhaled gas mixture on serum EPO levels induced by $3 \mathrm{~h}$ of normobaric arterial hypoxia $\left(8 \% \mathrm{O}_{2}\right)$ is shown in Fig. 1. Carbon dioxide led to a concentration-dependent suppression of EPO values. To investigate whether the inhibitory effect of hypercapnia was related to the decrease in $\mathrm{pH}$ or the increase in $\mathrm{PCO}_{2}$ or bicarbonate, we intended to 1 ) decrease $\mathrm{pH}$ without increasing $\mathrm{PCO}_{2}$ and bicarbonate and 2) elevate bicarbonate without decreasing $\mathrm{pH}$, by inducing a metabolic acidosis or alkalosis. Therefore animals were treated with

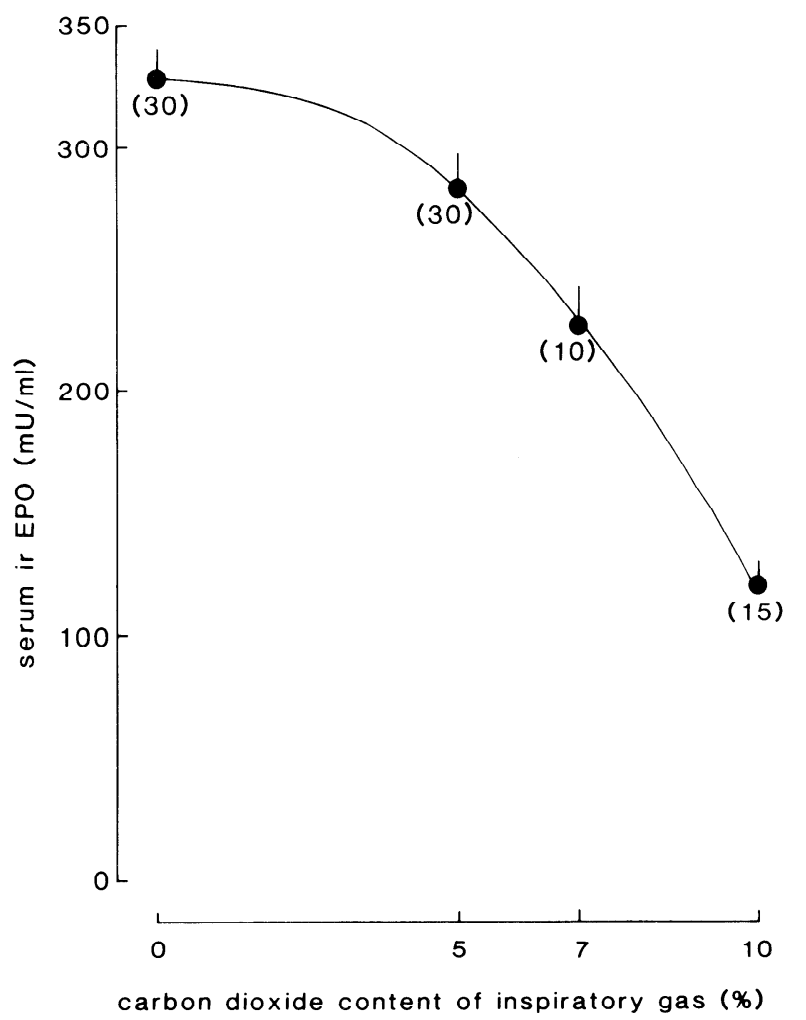

FIG. 1. Serum EPO levels after 3-h exposure to $8 \% \mathrm{O}_{2}, 0-10 \% \mathrm{CO}_{2}$, and balance $\mathrm{N}_{2}$ (means $\pm \mathrm{SE}$ ); values in parentheses are nos. of animals. Erythropoietin (EPO) levels were significantly reduced by addition of 5,7 , and $10 \% \mathrm{CO}_{2}$. 
TABLE 1. Peripheral venous $\mathrm{pH}$ and standard sodium bicarbonate concentrations in mice 1 and 3 h after injection of $\mathrm{NH}_{4} \mathrm{Cl}$ or $\mathrm{NaHCO}_{3}$

\begin{tabular}{|c|c|c|c|c|c|}
\hline & \multirow{2}{*}{ Controls } & \multicolumn{2}{|c|}{$\mathrm{NH}_{4} \mathrm{Cl}$} & \multicolumn{2}{|c|}{$\mathrm{NaHCO}_{3}$} \\
\hline & & $1 \mathrm{~h}$ & $3 \mathrm{~h}$ & $1 \mathrm{~h}$ & $3 \mathrm{~h}$ \\
\hline $\mathrm{pH}$ & $\begin{array}{c}7.342 \pm 0.04 \\
(8)\end{array}$ & $\begin{array}{c}7.207 \pm 0.03 \\
(6)\end{array}$ & $\begin{array}{c}7.248 \pm 0.05 \\
(7)\end{array}$ & $\begin{array}{c}7.467 \pm 0.03 \\
(5)\end{array}$ & $\begin{array}{c}7.431 \pm 0.02 \\
(5)\end{array}$ \\
\hline Standard bicarbonate & $\begin{array}{c}23.7 \pm 1.6 \\
(7)\end{array}$ & $\begin{array}{c}15.8 \pm 1.2 \\
(6)\end{array}$ & $\begin{array}{l}17.2 \pm 4.5 \\
\quad(6)\end{array}$ & $\begin{array}{c}32.3 \pm 1.4 \\
(5)\end{array}$ & $\begin{array}{c}31.4 \pm 1.7 \\
(5)\end{array}$ \\
\hline
\end{tabular}

Values are means $\pm \mathrm{SD}$; nos. in parentheses are nos. of animals. Values in all 4 treatment groups were significantly different from controls.

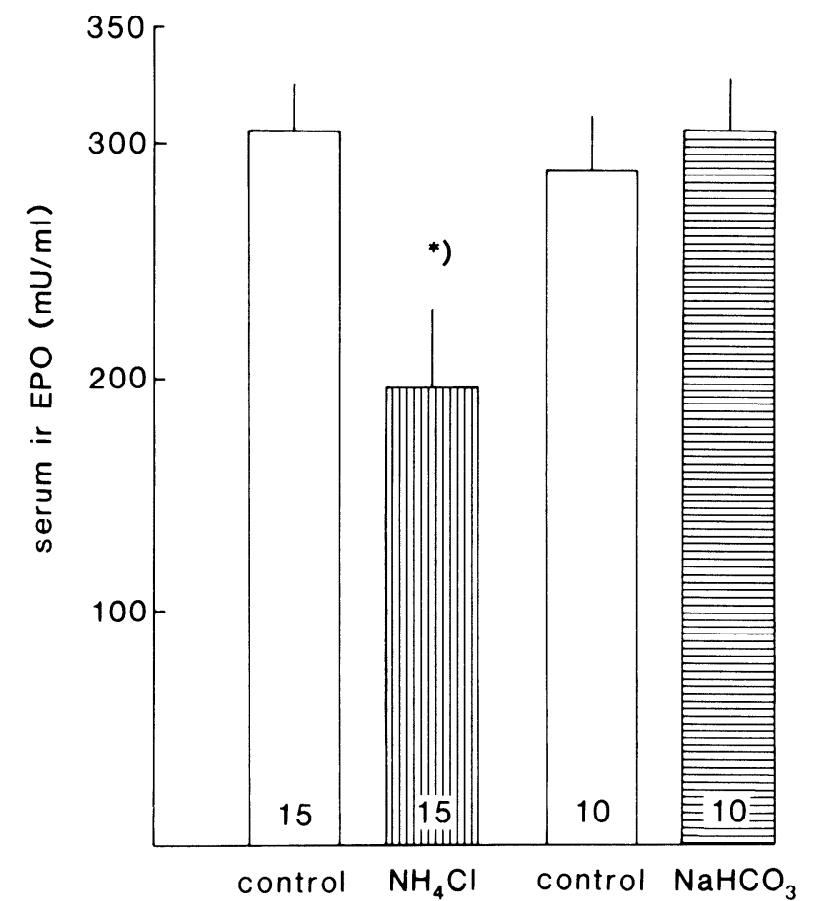

FIG. 2. Serum EPO levels after 3-h exposure to $8 \% \mathrm{O}_{2}$ and balance $\mathrm{N}_{2}$ in mice treated with $\mathrm{NH}_{4} \mathrm{Cl}$ or $\mathrm{NaHCO}_{3}$ (means $\pm \mathrm{SE}$ ); values in bars are nos. of animals; *significant difference from controls. Respective controls, treated with equimolar amounts of sodium chloride, were simultaneously exposed to hypoxia.

ammonium chloride or sodium bicarbonate. The effect of this treatment on peripheral venous $\mathrm{pH}$ and standard bicarbonate levels is given in 'Table 1 . It is obvious that they led to a marked metabolic acidosis and alkalosis, respectively, during the 3 -h period investigated.

To test any direct effect of metabolic acidosis and alkalosis on EPO in animals not exposed to hypoxia, EPO levels were measured in normoxic animals $3 \mathrm{~h}$ after application of ammonium chloride and sodium bicarbonate. Compared with control animals $[21 \pm 1.9(\mathrm{SE}) \mathrm{mU} /$ $\mathrm{ml} ; n=14$ ], values were slightly reduced after ammonium chloride $[14.9 \pm 1.1(\mathrm{SE}) \mathrm{mU} / \mathrm{ml} ; n=15]$ and slightly elevated under sodium bicarbonate $[24.4 \pm 2.4(\mathrm{SE}) \mathrm{mU} /$ $\mathrm{ml} ; n=15]$. However, only the difference between treatment groups reached statistical significance.

To study the effect of metabolic acidosis and alkalosis on EPO formation induced by arterial hypoxia, ammonium chloride and sodium bicarbonate were injected to animals before a 3 -h hypoxic exposure. The resulting EPO levels are depicted in Fig. 2. Metabolic acidosis significantly reduced EPO levels by $35 \%$, whereas metabolic alkalosis had no effect.

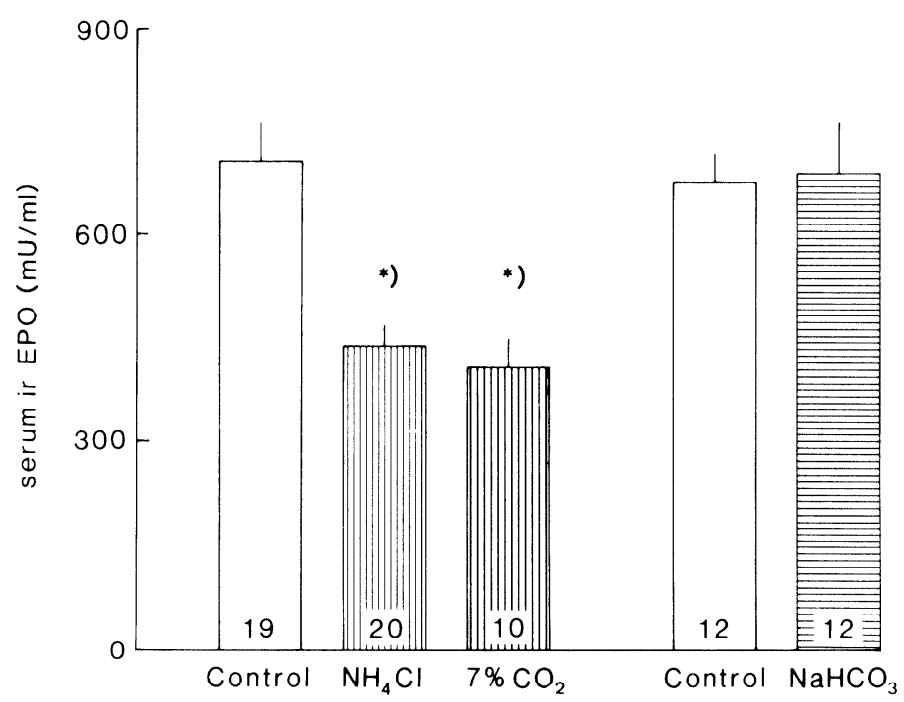

FIG. 3. Serum EPO levels after 3-h exposure to carbon monoxide $(0.1 \%)$ in animals treated with $\mathrm{NH}_{4} \mathrm{Cl}$ or $\mathrm{NaHCO}_{3}$ or exposed to carbon monoxide $(0.1 \%)$ and added carbon dioxide $(7 \%)$ (means $\pm \mathrm{SE}$ ); values in bars are nos. of animals; * significant difference from controls.
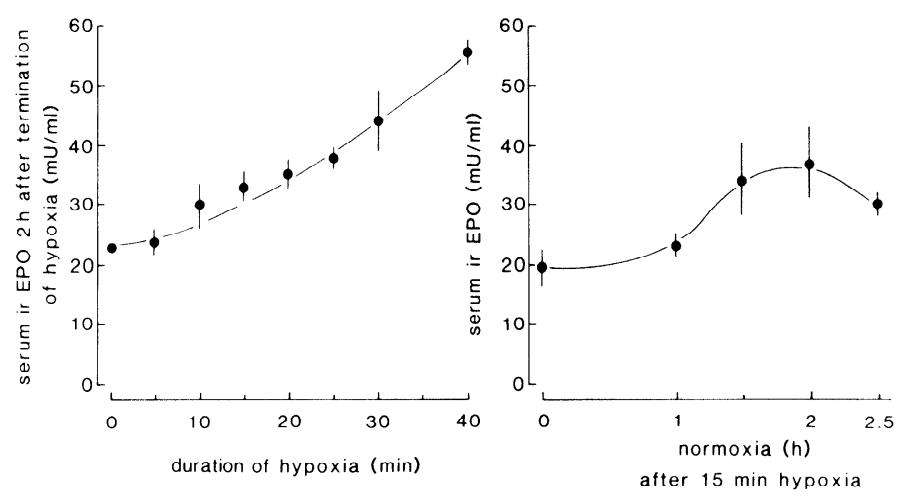

FIG. 4. Serum EPO levels in mice determined $2 \mathrm{~h}$ after exposure to 0 - to 40 -min hypoxia $\left(8 \% \mathrm{O}_{2}\right.$; left $)$ and EPO levels determined $0-2.5 \mathrm{~h}$ after exposure to 15 -min hypoxia $\left(8 \% \mathrm{O}_{2} ;\right.$ right $)$ (means $\pm \mathrm{SE} ; n=5-$ 7).

Effect of acid-base alterations on EPO production under carbon monoxide hypoxia. Figure 3 demonstrates the effect of metabolic acidosis, metabolic alkalosis, and respiratory acidosis $\left(7 \% \mathrm{CO}_{2}\right)$ on the increase in EPO levels induced by carbon monoxide $(0.1 \%)$. Similar to the 


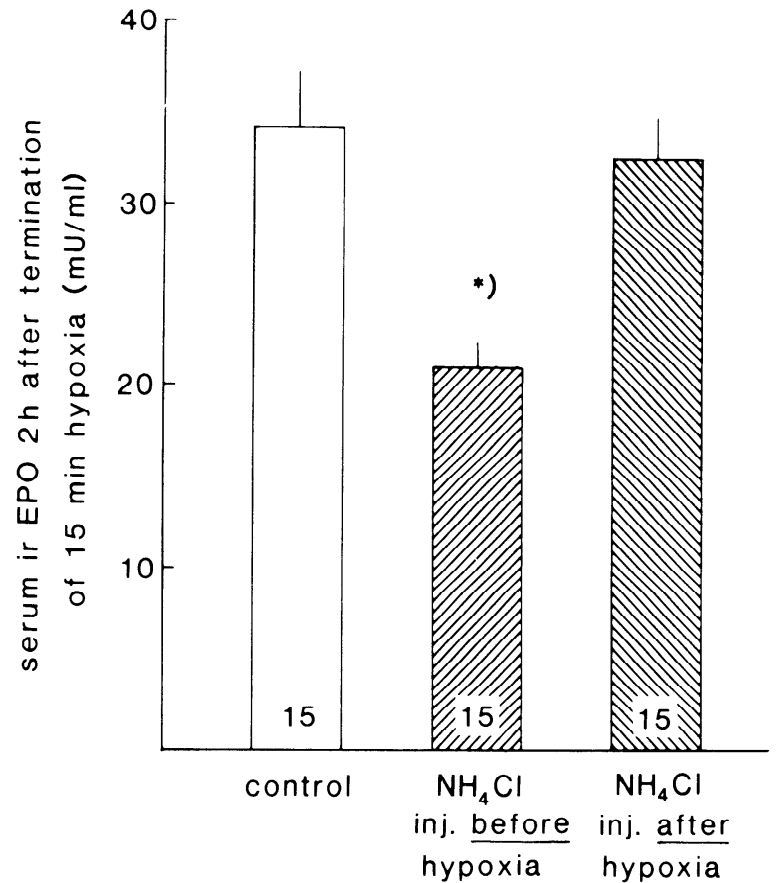

FIG. 5. Serum EPO levels determined $2 \mathrm{~h}$ after a hypoxic exposure of $15 \mathrm{~min}\left(8 \% \mathrm{O}_{2}\right)$ in animals injected with $\mathrm{NH}_{4} \mathrm{Cl}$ before onset of hypoxia or immediately after termination of hypoxia (means $\pm \mathrm{SE}$ ); values in bars are nos. of animals; *significant difference from controls.

results obtained with hypoxic hypoxia, respiratory as well as metabolic acidosis led to significantly diminished serum EPO levels (58 and $62 \%$ of control values, respectively), whereas metabolic alkalosis did not affect EPO values.

So far these results indicate that the observed suppression of EPO levels in response to hypoxic or carbon monoxide hypoxia is related to a decrease in $\mathrm{pH}$, irrespective of the way by which it has been brought about, and is independent of changes in $\mathrm{PCO}_{2}$ or serum bicarbonate levels.

Effect of acidosis on induction of EPO formation and EPO synthesis. To assess whether the triggering of EPO formation and/or EPO synthesis is sensitive to a decrease in $\mathrm{pH}$, we aimed at roughly separating both periods. We thereby define the trigger phase as time period during which hypoxia initiates the subsequent synthesis and release of EPO from the kidney. Under continuous hypoxia, when triggering and hormone synthesis overlap, EPO levels are known to be first elevated afer 1-2 h (3, $5,6,13,25)$. To separate an initial phase of triggering, animals were exposed to shorter periods of hypoxia $(8 \%$ $\mathrm{O}_{2} ; 5-40 \mathrm{~min}$ ) and then returned into normoxic atmosphere before determination of EPO levels to allow sufficient time for hormone production. Figure 4 (left) illustrates that EPO levels determined $2 \mathrm{~h}$ after the end of hypoxic exposures are slightly elevated when hypoxia had lasted for $10 \mathrm{~min}$ and increase with further prolongation of the hypoxic period. When EPO levels were determined between 1 and $2.5 \mathrm{~h}$ after a hypoxic stimulation of $15 \mathrm{~min}$, mean EPO levels were maximally elevated after $2 \mathrm{~h}$ of normoxia and thereafter tended to decline again (Fig. 4, right). A combination of 15-min hypoxia and 2 -h normoxia was therefore used in the following experiment, designed to determine the possible effect of a decrease in $\mathrm{pH}$ on the different phases of hypoxia-induced EPO formation. As illustrated in Fig. 5, ammonium chloride led to a significant reduction of EPO levels when injected before the onset of hypoxia and was ineffective when injected immediately after the end of hypoxic exposure.

\section{DISCUSSION}

Following the observation that patients with carbon dioxide retention due to pulmonary insufficiency may fail to develop polycycthemia to a degree expected from the extent of their hypoxia $(9,11)$, Faura and co-workers were, to our knowledge, the first to demonstrate a suppression of erythropoietic bioactivity when hypoxia was combined with hypercapnia (8). This effect was confirmed by several investigators $(1,3,14,20,25,26)$, and the concentration-dependent suppression of immunoreactive EPO levels with increasing carbon dioxide tension found in the present study (Fig. 1) is qualitatively in accordance with these findings. However, quantitatively, the effect of an increasing carbon dioxide concentration in the inhaled gas mixture appears more variable. In this study, we observed only a slight reduction by adding $5 \% \quad \mathrm{CO}_{2}$, whereas other investigators reported more pronounced effects $(25,26)$, which may be related, for example, to different changes in ventilation.

More important, the question arises about the mechanisms by which hypercapnia may suppress EPO levels. From our finding that both respiratory and metabolic acidosis result in diminished EPO levels in response to hypoxia (Figs. 2 and 3), it may be concluded that this effect is directly related to a decrease in systemic $\mathrm{pH}$ rather than an increase in $\mathrm{PCO}_{2}$. Also, changes in plasma bicarbonate levels appear not to mediate the inhibitory effect of hypercapnia, since they are oppositely affected in respiratory and metabolic acidosis, and, in addition, metabolic alkalosis due to an increase in bicarbonate levels had no effect on EPO values (Figs. 2 and 3). This latter finding indicates furthermore that the relationship between EPO levels and $\mathrm{pH}$ is not consistent over the whole biological range of hydrogen ion concentrations. The respiratory alkalosis normally occuring under hypoxia appears to enhance EPO levels, since its prevention by addition of $5 \% \mathrm{CO}_{2}$ reduces EPO titers, whereas any further alkalinization does not further enhance hypoxiainduced EPO values.

The increase of serum EPO after hypoxia is determined by as-yet-undefined mechanisms triggering an enhanced rate of EPO gene transcription, the subsequent increase in EPO synthesis, and, finally, the rate of hormone clearance. To determine, which of these parameters is sensitive to a decrease in $\mathrm{pH}$, we attempted to roughly separate an initial trigger phase from a subsequent phase of hormone synthesis and metabolism. Animals were exposed to hypoxia for $15 \mathrm{~min}$ and allowed another $2 \mathrm{~h}$ in normoxia before determination of EPO levels (Fig. 4). Acidosis did only reduce EPO levels when initiated before the hypoxic pulse. When acidosis was applied immediately after termination of the hypoxic period, there was no change in EPO levels. From these 
results, the conclusions may be drawn that the hypoxic trigger mechanisms of EPO formation are sensitive to acidosis, whereas neither the synthesis of EPO is inhibited nor the clearance rate enhanced by a decrease in $\mathrm{pH}$.

Because the trigger mechanisms of EPO formation are thought to be mainly determined by peripheral oxygen availability (cf. Ref. 5), it appears reasonable to consider possible pathways by which a decrease in systemic $\mathrm{pH}$ might alter this parameter. Because acidosis stimulates chemoreceptors, which in turn potentiate increased ventilation under hypoxia, animals subjected to hypercapnic hypoxia display higher arterial oxygen tensions and hemoglobin saturations than those exposed to normo- or hypocapnic hypoxia. Thus in previous studies in which rats or rabbits were exposed to hypoxia of a degree comparable with that in our experiments $\left(7.5-8.8 \% \mathrm{O}_{2}\right)$ the addition of $5-6 \% \mathrm{CO}_{2}$ to the inspirated gas mixture was shown to increase arterial $\mathrm{Po}_{2}$ by $9-16 \mathrm{mmHg}$ (from 26-36 mmHg under hypocapnic hypoxia to $42-45 \mathrm{mmHg}$ after addition of $\left.\mathrm{CO}_{2}\right)(3,14,23,25)$. Increased ventilation is, however, ineffective in increasing peripheral oxygenation when diminished oxygen-carrying capacity causes the hypoxia. Nevertheless, we found also an inhibitory effect of acidosis on EPO levels in animals exposed to carbon monoxide (Fig. 3), indicating that the increased ventilation is not the principal mechanism by which EPO formation is attenuated. This conclusion is in accordance with a previous study in which anesthetized rabbits were shown to develop less erythropoietic activity on hypercapnic hypoxia, although the increase in arterial oxygen content was prevented by controlled ventilation (1).

The effect of hypercapnia on renal hemodynamics is variable, depending on the experimental conditions (4, $19,23)$, but renal blood flow and thereby renal oxygen supply may be increased (4). However, EPO formation has been shown to be relatively insensitive to alterations in renal perfusion (17), probably because changes in perfusion vary both oxygen supply and oxygen consumption in parallel (cf. Ref. 5). That acidosis inhibits EPO formation via a specific effect on renal function appears unlikely, because extrarenal EPO formation was also shown to be attenuated by hypercarbia (26).

Several investigators have emphasized a possible role of alterations in the oxygen affinity of hemoglobin for peripheral tissue oxygenation and subsequently EPO formation $(12-14,16,20,25)$. Thus an increase in oxygen affinity may enhance EPO formation in normoxic animals (12), and hypoxic stimuli for EPO are associated with an increased oxygen affinity, whereas the inhibitory effect of acidosis is associated with decreased oxygen affinity $(3,14,20,25)$. Direct studies on the effect of oxygen affinity of hemoglobin on EPO formation suggest, however, that its relative role decreases with increasing degrees of hypoxia (12). Furthermore, a significant contribution of changes of the oxygen affinity of hemoglobin to the suppression of EPO formation by acidosis could not be substantiated in certain experimental settings. Miller and Howard (14), for example, found significant differences in plasma EPO concentrations between ane- mic rats exposed to normo- or hypercapnic hypoxia for $18 \mathrm{~h}$, despite no differences in arterial $\mathrm{PO}_{2}, \mathrm{O}_{2}$ saturation, or $\mathrm{P}_{50}$ values (14).

Although these observations cast some doubt that a reduction in the oxygen affinity of hemoglobin is the sole mechanism by which a decrease in $\mathrm{pH}$ inhibits EPO formation, definite understanding of the role of increased peripheral oxygenation for the inhibition of EPO formation by acidosis will await identification and isolation of the cellular production sites, to determine their sensitivity to changes in $\mathrm{pH}$. It is of interest that several reports demonstrated a protective effect of acidosis against hypoxic injury at a cellular level $(2,10,18,24)$, and one might speculate that this has bearings on the signals linking EPO formation to hypoxia.

The antiserum used in the radioimmunoassay for erythropoietin was a generous gift from Dr. Peter Hirth, Boehringer Mannheim, FRG. Werner Gehret did the artwork.

This study was in part financially supported by the Swiss National Science Foundation Grant 3.165.88 and the Hartmann Müller Stiftung für Medizinische Forschung. K.-U. Eckardt was supported by a fellowship from the German Research Foundation.

Address for reprint requests: K.-U. Eckardt, Physiologisches Institut, Universität Zürich, Winterthurerstrasse 190, CH 8057 Zürich, Switzerland.

Received 7 August 1989; accepted in final form 23 October 1989.

\section{REFERENCES}

1. BAKer, R., J. R. ZuCALI, B. J. BAKER, AND J. Strauss. Erythropoietin and intrarenal oxygenation in hypercapnic versus normocapnic hypoxemia. Adv. Exp. Med. Biol. 169: 597-609, 1984.

2. Burnier, M., V. J. van Putten, A. Schieppati, and R. W. ScHRIER. Effect of extracellular acidosis on ${ }^{45} \mathrm{Ca}$ uptake in isolated hypoxic proximal tubules. Am. J. Physiol. 254 (Cell Physiol. 23): C839-C846, 1988.

3. Cohen, R. A., M. E. Miller, J. F. Garcia, G. Moccia, and E. P. CRONKITE. Regulatory mechanism of erythropoietin production: effects of hypoxemia and hypercarbia. Exp. Hematol. 9: 513-521, 1981.

4. Daugherty, R. M., Jr., J. B. Scott, J. M. Dabney, and F. J. HADDY. Local effects of $\mathrm{O}_{2}$ and $\mathrm{CO}_{2}$ on limb, renal, and coronary vascular resistance. Am. J. Physiol. 213: 1102-1110, 1967.

5. ECKardT, K.-U., AND C. Bauer. Erythropoietin in health and disease. Eur. J. Clin. Invest. 19: 117-127, 1989.

6. ECKardT, K.-U., A. Kurtz, AND C. BAUER. Regulation of erythropoietin formation is related to proximal tubular function. Am. J. Physiol. 256 (Renal Fluid Electrolyte Physiol. 25): F942-F947, 1989.

7. Eckardt, K.-U., A. Kurtz, P. Hirth, P. Scigalla, L. WieczoREK, AND C. BAUER. Evaluation of the stability of human erythropoietin in samples for radioimmunoassay. Klin. Wochenschr. 66: $241-245,1988$.

8. Faura, J., C. W. Gurney, And W. Fried. The effect of carbon dioxide on erythropoiesis. Ann. NY Acad. Sci. 149: 456-461, 1968.

9. Gallo, R. C., W. Fraimow, R. T. CathCart, and A. J. Erslev. Erythropoietic response in chronic pulmonary disease. Arch. Int. Med. 113: 559-568, 1964.

10. Gores, G. J, A.-L. Nieminen, B. A. Wray, B. Herman, and J. I. I.EMASTERS. Intracellular $\mathrm{pH}$ during "chemical hypoxia" in cultured rat hepatocytes. Protection by intracellular acidosis against the onset of cell death. J. Clin. Invest. 83: 386-396, 1989.

11. Hammersten, J. F., W. H. Whitcomb, P. C. Johnson, And J. R. LOWELL. The hematololgic adaptation of patients with hypoxia due to pulmonary emphysema. Annu. Rev. Tuberc. 78: 391, 1958.

12. LeChermanN, B., AND W. JelKmanN. Erythropoietin production in normoxic and hypoxic rats with increased blood oxygen affinity. Respir. Physiol. 60: 1-8, 1985.

13. Miller, M. E. The interaction between the regulation of acid-base and erythropoietin production. Blood Cells 1: 449-465, 1975.

14. MilleR, M. E., AND D. How $A$ RD. Modulation of erythropoietin 
concentrations by manipulation of hypercarbia. Blood Cells 5: 389 403, 1979.

15. Miller, M. E., D. Howard, F. Stohlman, and P. Flanagan. Mechanism of erythropoietin production by cobaltous chloride. Blood 44: 339-346, 1974.

16. Miller, M. E., M. RøRTh, H. H. Parving, D. Howard, I. Reddington, C. R. Valeri, and F. Stohlman, JR. pH effect on erythropoietin response to hypoxia. N. Engl. J. Med. 288: 706-710, 1973.

17. Pagel, H., W. Jelkmann, and C. Weiss. A comparison of the effects of renal artery constriction and anemia on the production of erythropoietin. Pfluegers Arch. 413: 62-66, 1988.

18. Penttila, A., AND B. J. TRUMP. Extracellular acidosis protects ehrlich ascites tumor cells and rat renal cortex against anoxic injury. Science Wash. DC 185: 277-278, 1974.

19. Rose, C. E., Jr., D. P. Kimmel, R. L. Godine, Jr., D. L. Kaiser, AND R. M. CAREY. Synergistic effects of acute hypoxemia and hypercapnic acidosis in conscious dogs. Circ. Res. 53: 202-213, 1983.

20. SChOoley, J. C., AND L.-J. Mahlmann. Hypoxia and the initiation of erythropoietin production. Blood Cells 1: 429-448, 1975.
21. Schuster, S. J, E. V. Badiavas, P. Costa-Giomi, R. Weinmann, A. J. ERslev, and J. Caro. Stimulation of erythropietin gene transcription during hypoxia and cobalt exposure. Blood 73: 13-16, 1989.

22. Shanley, P. F., J. I. Shapiro, L. Chan, T. J. Burke, And G. C. Johnson. Acidosis and hypoxic medullary injury in the isolated perfused kidney. Kidney Int. 34: 791-796, 1988.

23. WAIKFR, B. R., AND B. I. BRIZ7.FF. Renal vascular response to combined hypoxia and hypercapnia in conscious rats. Am. J. Physiol. 254 (Regulatory Integrative Comp. Physiol. 23): R552-R558, 1988.

24. WeINBERG, J. M. Oxygen deprivation-induced injury to isolated rabbit kidney tubules. J. Clin. Invest. 76: 1193-1208, 1985.

25. Wolf-Priessnitz, J., J. C. Schooley, and L.-J. Mahlmann. Inhibition of erythropoietin production in unanesthetized rabbits exposed to an acute hypoxic-hypercapnic environment. Blood 52 : 153-162, 1978.

26. ZuCAli, J. R., M. LeE, AND E. A. Mirand. Carbon dioxide effects on erythropoietin and erythropoiesis. J. Lab. Clin. Med. 92: 648$655,1978$.

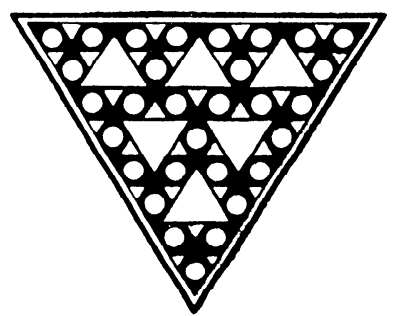

